\title{
Corrigendum: DICER1 and microRNA regulation in post-traumatic stress disorder with comorbid depression
}

\author{
Aliza P. Wingo, Lynn M. Almli, Jennifer S. Stevens, Torsten Klengel, Monica Uddin, Yujing Li, \\ Angela C. Bustamante, Adriana Lori, Nastassja Koen, Dan J. Stein, Alicia K. Smith, Allison E. Aiello, \\ Karestan C. Koenen, Derek E. Wildman, Sandro Galea, Bekh Bradley, Elisabeth B. Binder, Peng Jin, Greg Gibson \\ \& Kerry J. Ressler
}

Nature Communications 6:10106 doi: 10.1038/ncomms10106 (2015); Published 3 Dec 2015; Updated 3 Mar 2016

The original version of this Article contained an error in the spelling of the author Jennifer S. Stevens, which was incorrectly given as Jennifer J. Stevens. Furthermore, in Fig. 5, the titles for panels a and b were inadvertently switched. Both of these errors have now been corrected in the PDF and HTML versions of the Article.

This work is licensed under a Creative Commons Attribution 4.0 International License. The images or other third party material in this article are included in the article's Creative Commons license, unless indicated otherwise in the credit line; if the material is not included under the Creative Commons license, users will need to obtain permission from the license holder to reproduce the material. To view a copy of this license, visit http://creativecommons.org/licenses/by/4.0/ 